\title{
Vps4b heterozygous mice do not develop tooth defects that replicate human dentin dysplasia I
}

\author{
Aiqin $\mathrm{Hu}^{1}$, Ting $\mathrm{Lu}^{1,2}$, Danna Chen ${ }^{1}$, Jin Huang ${ }^{1}$, Weiwei Feng ${ }^{1}$, Yanjun $\mathrm{Li}^{1}$, Dan Guo ${ }^{1}$, Xiangmin $\mathrm{Xu}^{1,3}$, \\ Dong Chen ${ }^{1,4^{*}}$ and Fu Xiong ${ }^{1,3^{*}}$ (D)
}

\begin{abstract}
Background: Vacuolar protein sorting-associated protein 4B (VPS4B) is a member of the ATP enzyme AAA protein family, and is mainly involved in protein degradation and cell membrane fusion. Recently, a dominant mutation in this gene was identified in human dentin dysplasia type I (DD-I). Herein, we report the generation of Vps $4 b$ knockout (Vps4b KO) mice; however, the homozygous Vps4b KO mutation was embryonic lethal at the early stages of embryo development, and we therefore report the results of heterozygous mutant mice.

Results: Mice heterozygous for Vps4b did not develop tooth defects replicating human DD-I. Immunohistochemistry showed that gene KO was successful, as there was decreased expression of Vps4b in heterozygous mice; hematoxylin and eosin (H\&E) staining also showed that the width of the pre-dentin zone was increased in heterozygous mice, although the arrangement of the odontoblasts was not significantly different from wild-type (WT) mice. However, H\&E staining showed no obvious abnormalities in the bones of heterozygous mice. Moreover, stereomicroscopic and X-ray radiography results indicated no abnormal manifestations in teeth or bones. Furthermore, statistical analysis of the volume and density of dentin and enamel, as well as skeletal analysis, including the volume and separation of trabecular bone analyzed by micro-CT, all showed no differences between Vps $4 b$ heterozygotes and WT mice. In addition, there also were no significant differences in bone or cartilage mineralization as evaluated by Alcian blue-Alizarin red staining.
\end{abstract}

Conclusions: The heterozygous Vps4b KO mice do not develop tooth defects that replicate human DD-I and this is likely to be due to differences in tooth development between the two species. Consequently, further studies are needed to determine whether mice are an appropriate animal model for human tooth diseases.

Keywords: Vacuolar protein sorting 4B, Dentin dysplasia, Vps4b ${ }^{+/-}$mice, Phenotype

\section{Background}

Vacuolar protein sorting 4 (VPS4) is one of the major members of the ATP enzyme AAA protein family and is known to promote protein degradation and cell membrane fusion [1-3]. In humans, two homologues, VPS4A and $V P S 4 B$, both of which share $80 \%$ homology, have been identified $[4,5]$. The gene encoding VPS4A is located on chromosome 16, while the gene encoding $V P S 4 B$ is located on chromosome 18. Functional studies

\footnotetext{
* Correspondence: chendongfmmu@163.com; xiongfu@smu.edu.cn 'Department of Medical Genetics, School of Basic Medical Sciences, Southern Medical University, No.1023, Shatai South Road, Guangzhou 510515, People's Republic of China

Full list of author information is available at the end of the article
}

show that the two genes are associated with the endosomal compartment and are involved in intracellular protein transport $[3,6]$. Similarly, the mouse also has two homologues: Vps4a and Vps4b. The mouse Vps4a gene has been mapped to a region of chromosome $8 \mathrm{D}$ that shares homology of synteny with human chromosome $16 \mathrm{q} 22$, while the mouse Vps $4 b$ gene has been mapped to a region of chromosome 1E3 that shares homology of synteny with human chromosome 18q21-q22 [7].

Recent studies have found that VPS4B primarily participates in lysosomal degradation pathways, intracellular protein transport, viral body budding, and regulation of the different stages of cell division $[8,9]$. Previous work

(c) The Author(s). 2019 Open Access This article is distributed under the terms of the Creative Commons Attribution 4.0 International License (http://creativecommons.org/licenses/by/4.0/), which permits unrestricted use, distribution, and 
from our lab indicated that the VPS4B gene was one of the pathogenic genes associated with DD-I, which regulates tooth development via interaction with Wnt/B-catenin canonical signaling [10]. A splicing mutation, IVS7 $+46 \mathrm{C}>\mathrm{G}$, genetically linked to DD-I in an extended Chinese family, was identified in VPS4B, and has been proven to cause DD-I in a loss-of-function manner. In addition, our investigation of tooth development in zebrafish or in vitro revealed a function for the $V P S 4 B$ gene in tooth development $[10,11]$.

In this study, we carried out further studies on the effects of $V P S 4 B$ on tooth development and determined the physiological functions of $V P S 4 B$. We generated a $V p s 4 b$ knockout (KO) mouse model and analyzed the phenotype of teeth and bones from these mice. The results indicate that heterozygous $\mathrm{KO}$ mice do not develop tooth defects that replicate human DD-I.

\section{Methods}

\section{Transgenic mice}

All four Vps4b $\mathrm{KO}$ mice were heterozygous (HET) $\left(V p s 4 b^{+/-}\right)$and produced both wild-type (WT) $\left(V p s 4 b^{+++}\right)$ and homozygous mutant $\left(V p s 4 b^{-/-}\right)$offspring. The mouse strain is C57BL/6 J from the United States. These mice with gene knockout were provided by Nanjing UniversityNanjing Biomedical Research Institute. Mice were bred in SPF - grade barrier environments with the SOP regulations of the barrier facility. The temperature and humidity of laboratory were kept at $23 \pm 2{ }^{\circ} \mathrm{C}$ and $55 \pm 5 \%$. The basket and bedding were replaced every twice week. The 12 $\mathrm{h} / 12 \mathrm{~h}$ alternating light/dark illumination method were used. The above-mentioned materials were sterilized with high temperature of $121^{\circ} \mathrm{C}$ for $30 \mathrm{~min}$. The mice we used were 1, 3, 6, and 9-month-old from birth. They were euthanized using compressed $5 \% \mathrm{CO} 2$ gas produced by the delivery systems of Shanghai yuyan science instrument company. The dosage was calculated according to the weight of mice. About 70 days after birth, sexually mature male and female mice were caged in a 1:1 ratio to reproduce. Two groups of comparison are involved. For all experiments, significance between groups was calculated using Student's t-test. Each group contains at least three mice. Each experiment was repeated at least three times, and a consistent result was accepted [12].

Polymerase chain reaction (PCR) primers were used to detect the 999 base pair (bp) deletion sequence and are shown in Fig. 1a. Theoretically, if the mouse was WT, the PCR product was $1383 \mathrm{bp}$, and if the mouse was a homozygous mutant, the corresponding PCR product was $384 \mathrm{bp}$. Finally, if the mouse was HET, two PCR products were generated, one of each length. However, in actual experiments, HET mice contained the same primer binding sites for each product and therefore the products competed with one another; consequently the knockout alleles were easier to expand than the WT alleles. A primer, reverse2 (R2), inside the deleted

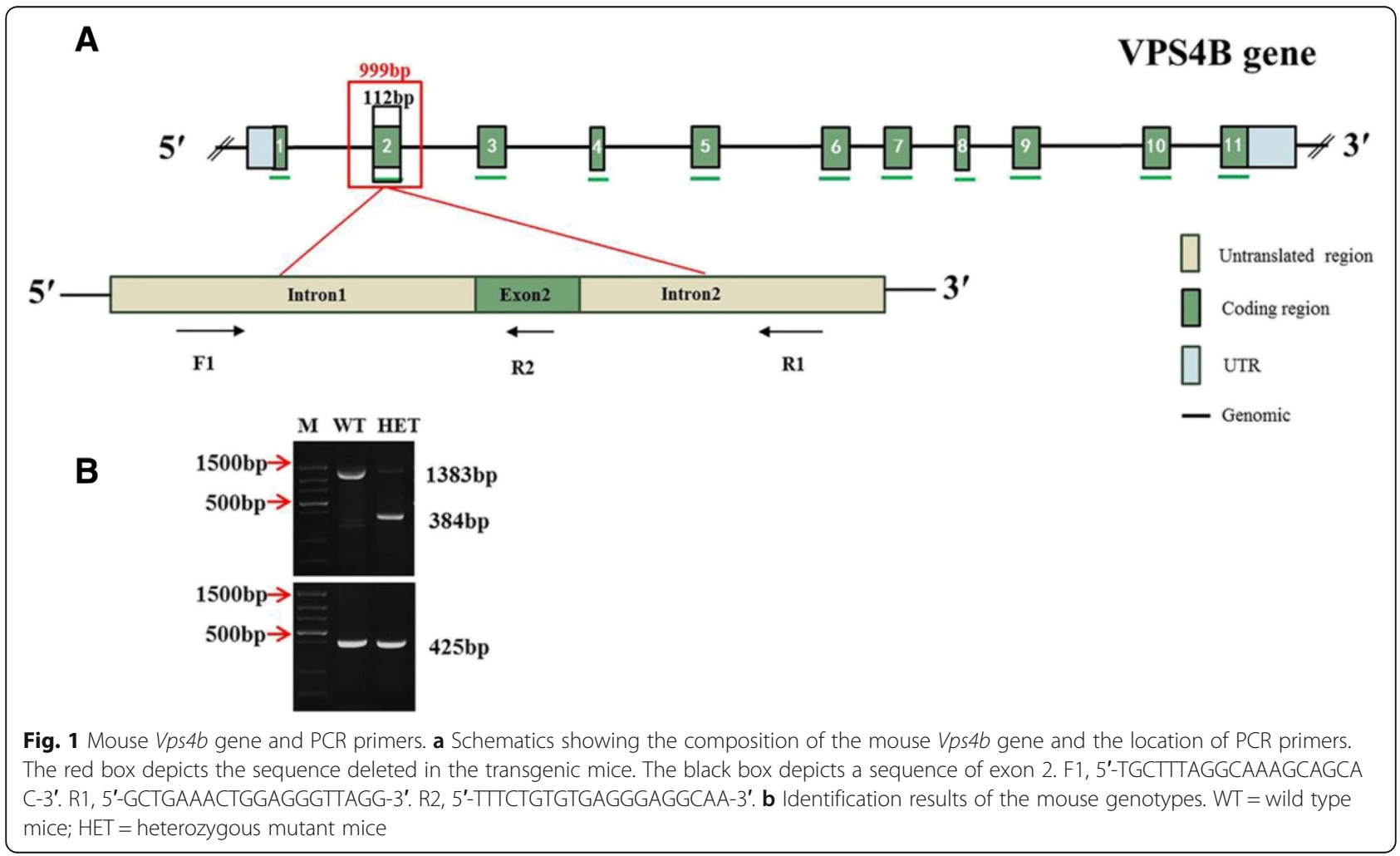


sequence was designed to avoid identification errors, and F1 / R2 were used for another PCR reaction. The WT alleles were still present with a 425 bp band while the homozygous mutant contained no band. Using two pairs of primers, we identified mice as WT if they generated a $1383 \mathrm{bp}$ and a $425 \mathrm{bp}$ PCR product; as HET if they generated a $384 \mathrm{bp}$ and $425 \mathrm{bp}$ PCR product; and as homozygous in they generated only a $384 \mathrm{bp}$ PCR product. However, as the homozygous allele was embryonic lethal, only WT and HET mice were generated (Fig. 1b).

\section{Hematoxylin \& eosin (H\&E) and immunohistochemical (IHC) staining}

The mandibular muscle and gingival tissue were dissected from both WT and HET mice at 1, 3, and 6 months of age. H\&E and IHC analysis were performed as previously described [13]. The stained sections were observed and photographed under an inverted fluorescence microscope (Olympus company, Tokyo, Japan). H\&E staining was used to observe whether dental pulp cavities were blocked; to identify whether the thickness of the dentin was normal; and to determine the arrangement of odontoblasts. A VPS4B antibody (C-13; Santa Cruz Biotechnology, Santa Cruz, CA, USA) was used in IHC analyses to observe the expression of VPS4B in mouse teeth.

\section{Plain X-ray radiography and stereomicroscopy}

Both WT and HET mice at 3 and 9 months of age, with similar weights, were examined using whole body X-ray imaging to identify any abnormalities in the thickness and mineralization of the skull, ribs, spine, or coccyx. We also employed microcomputed tomography (micro$\mathrm{CT}$ ) to observe the teeth and femurs, including the pulp cavity and the ultrastructure of trabecular bone. Mice were also examined under a stereomicroscope for pit depth, occlusal fissures in the teeth, and dental crown height.

\section{Skeletal Alcian blue-alizarin red staining}

Mice were sacrificed and the skin, muscle and visceral tissue were removed. Skeletal specimens were fixed in 95\% ethanol for 3 days, then immersed in acetone for 48 $\mathrm{h}$ to remove fat. Specimens were then soaked in freshlyprepared staining solution to stain the whole skeletons. The staining time was dependent on the age of the mice. Fetal and juvenile specimens were treated for 1 day, while adult specimens were treated for 3-7 days. Skeletal specimens were then immersed in $1 \% \mathrm{KOH}$ solution for 24-48 $\mathrm{h}$ and transferred to a series of glycerol solutions with $1 \% \mathrm{KOH}$ solution (volume ratio of $1: 4,1: 1$, and 4:1, respectively) until the surrounding tissues were completely removed. After bone tissue had become transparent, specimens were immersed in glycerol for long-term preservation. Mineralized bone tissues stained red, while cartilage stained blue.

\section{Microcomputed tomography (micro-CT)}

Procedures for the preparation of mandible samples and micro-CT were as previously described [13]. Briefly, 3-, 6-, and 9-month-old mice were euthanized using compressed $5 \% \mathrm{CO}_{2}$ gas and their mandibles and femurs were removed and fixed overnight with $4 \%$ buffer-saturated paraformaldehyde. Bones were scanned using a Scanco80 $(\mu 80)$ system (Scanco Medical AG, Bassersdorf, Switzerland). The instrumental isotropic resolution was $10 \mu \mathrm{m}$ and the iso-surface was reconstructed using two-dimensional raw data using MicroView analysis software (GE Healthcare, Little Chalfont, UK). The image analysis method was based on Hounsfield units (2800 units) and region-grow algorithms to segment image data defining separate anatomical structures. Images were reconstructed with Mimics ${ }^{\bullet} 14.0$ (Materialise, Leuven, Belgium) software using a global threshold of 1400 Hounsfield units.

\section{Scanning electron microscopy (SEM)}

Mice at 3 and 6 months of age were decapitated to separate the mandibles. Tissues were dissected from mandibles and were placed in 4\% paraformaldehyde for $24 \mathrm{~h}$. The tissue was dehydrated using increasing alcohol concentrations $(70,80,90$, and $100 \%$ ) for 1 week, then soaked in different resin gradients, and finally embedded in the resin. Finally, the tissue was cut with a hard tissue slicer and ground down to fine powder. The jelly samples were sprayed and examined with a Hitachi S3400 N SEM (Tokyo, Japan) to compare differences in the dentin tubule arrangement and density between the different genotypes.

\section{Statistical analysis}

For all experiments, significance between groups was calculated using Student's t-test. The quantified results are shown as the mean $\pm \mathrm{SD} ; P<0.05$ was considered to be statistically significant.

\section{Results}

Effects of heterozygous expression of the VPS4B gene on teeth

Pre-dentin is a layer of dentin that forms prior to dentin mineralization. Pre-dentin attaches to the pulp cavity; and its thickness represents the mineralization rate of dentin [12]. In other words, the thicker the pre-dentin layer, the slower the mineralization. The results of $\mathrm{H} \& \mathrm{E}$ staining of teeth isolated from 1-, 3-, and 6-month-old mice indicated that the width of the pre-dentin layer was increased, but the arrangement of the odontoblasts 
showed no significant differences between HET mice and WT mice; none of the HET or WT mice displayed pulp cavity obstructions (Fig. 2).

Dentin is secreted by the odontoblast layer, a single layer of cells close to the exterior of the pulp cavity [14]. The results of immunohistochemical staining suggested that the expression of VPS4B in HET mice was lower than in WT mice, and was specific to the odontoblast cell layer (Fig. 3a-f). As all the mice aged, their teeth became worn and the pits and fissures in the occlusal surface of the teeth became shallow. However stereomicroscopy found no significant difference in the appearance of the teeth or the wear of the occlusal surface between WT and HET mice (Fig. 3g-l).
Micro-CT was used to examine the tooth pulp cavity; no significant differences were found between the two genotypes (Fig. 4a-d). We also analyzed the volume and density of dentin and enamel of three photographed teeth on one mandible of 3- and 6-month -old mice. Specifically, the dentin and enamel ranges of the three teeth were drawn to calculate the volume and density of each, with results indicating no significant differences between WT and HET mice. The volume of dentin increased with increasing age, while that of enamel decreased with increasing age, probably due to tooth degeneration. Nevertheless, the mineralization amount of dentin and enamel remained constant (Fig. 4e-h).

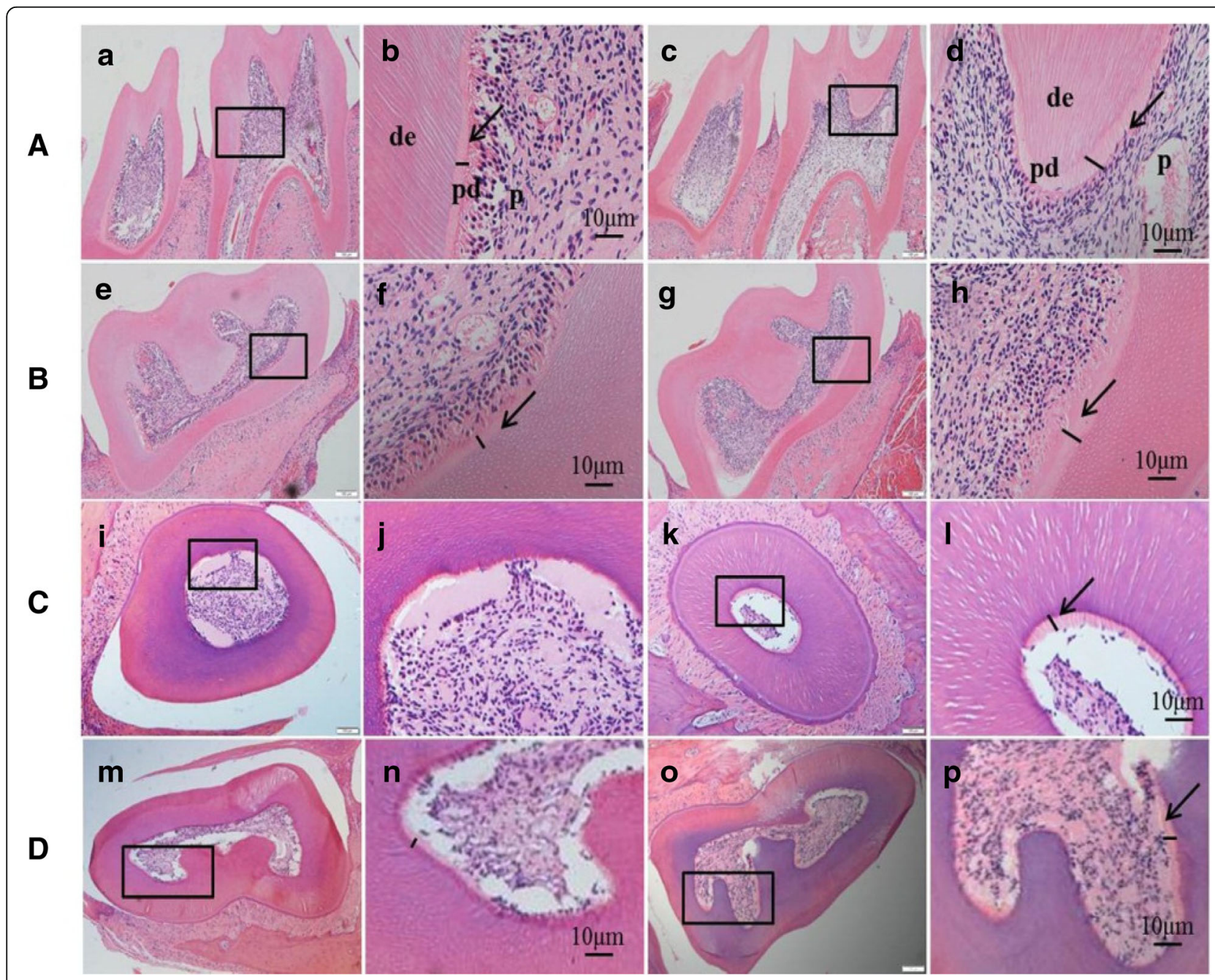

Fig. 2 Histopathological analysis of mandibular first molars of mice with increased pre-dentin width. Histopathological analysis of mandibular first molars in 1 (A, B), 3 (C), and 6 (D) month-old mice. Compared with WT mice (a, e, i, and m), the pre-dentin width was reduced and the mineralized dentin width was increased in heterozygous mice ( $c, g, k$, and 0$)$. A Longitudinal sections of a representative 1-month-old mouse tooth. B, C, and D Cross-sections of representative 1-, 3-, and 6-month-old mouse teeth. High-power magnification (b, d, f, h, j, l, $n$, and p) from the area inside the black box in low-magnification images (a, $c, e, g, i, k, m$, and o). The black arrows refer to the inner pre-dentin. Abbreviations: de, dentin; p, pulp; pd., pre-dentin 


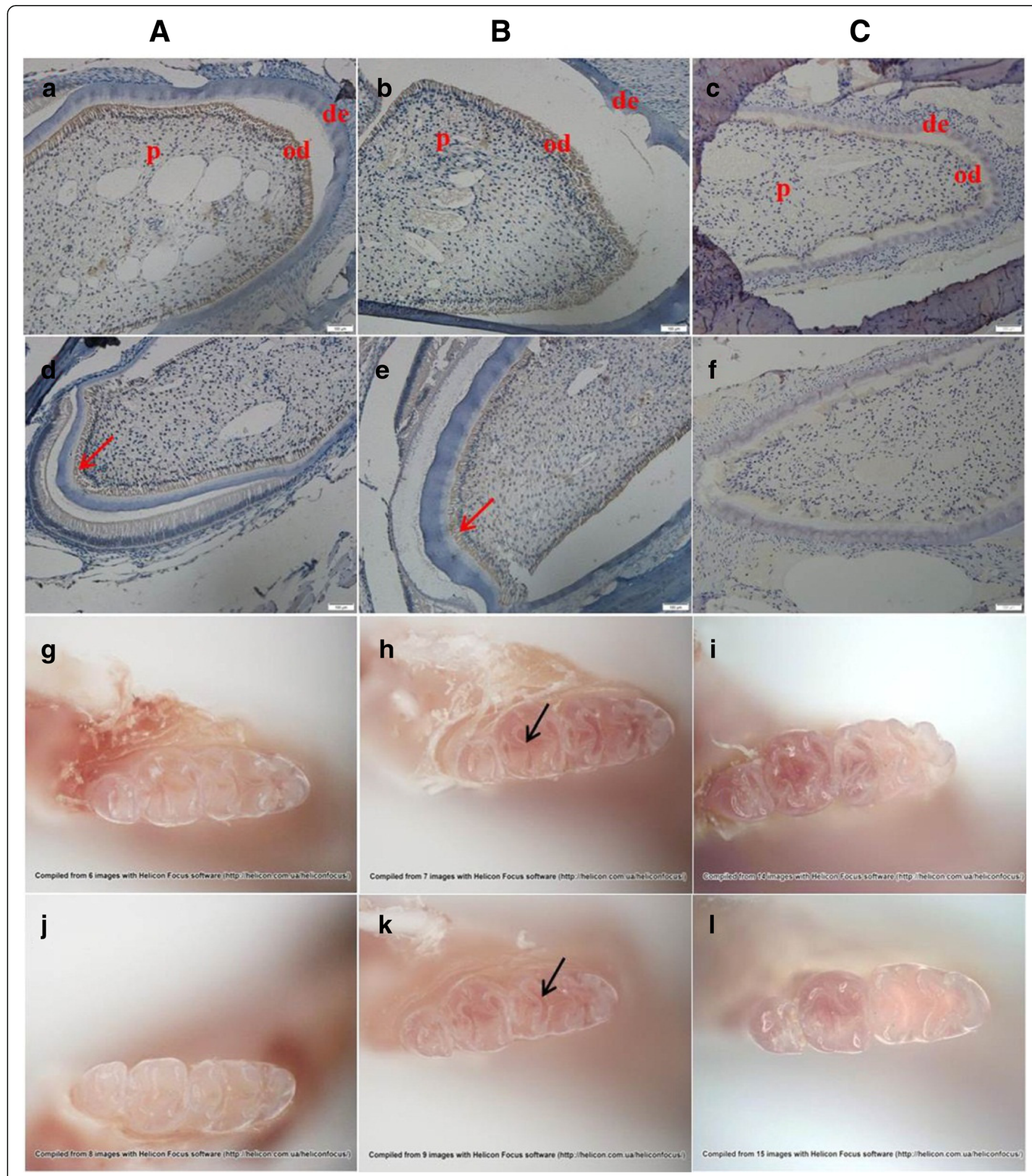

Fig. 3 Expression of VPS4B in mouse teeth and stereomicroscopy of mouse teeth. A, B, and C Representative 1-, 3-, and, 6-month-old mouse teeth, respectively. Strong VPS4B signals (brown) were observed in the odontoblasts of WT mice (a, b, and c), whereas heterozygous mice (d, e, and $f$ ) displayed markedly reduced signals. The red arrows indicate the odontoblast cell layer and the black arrow indicates the pits and fissures of teeth at the occlusal surface. Abbreviations: de, dentin; p, pulp; od, odontoblast (a, b, c, g, h, and i are WT mice; d, e, f, j, k, and I are HET mutant mice) 


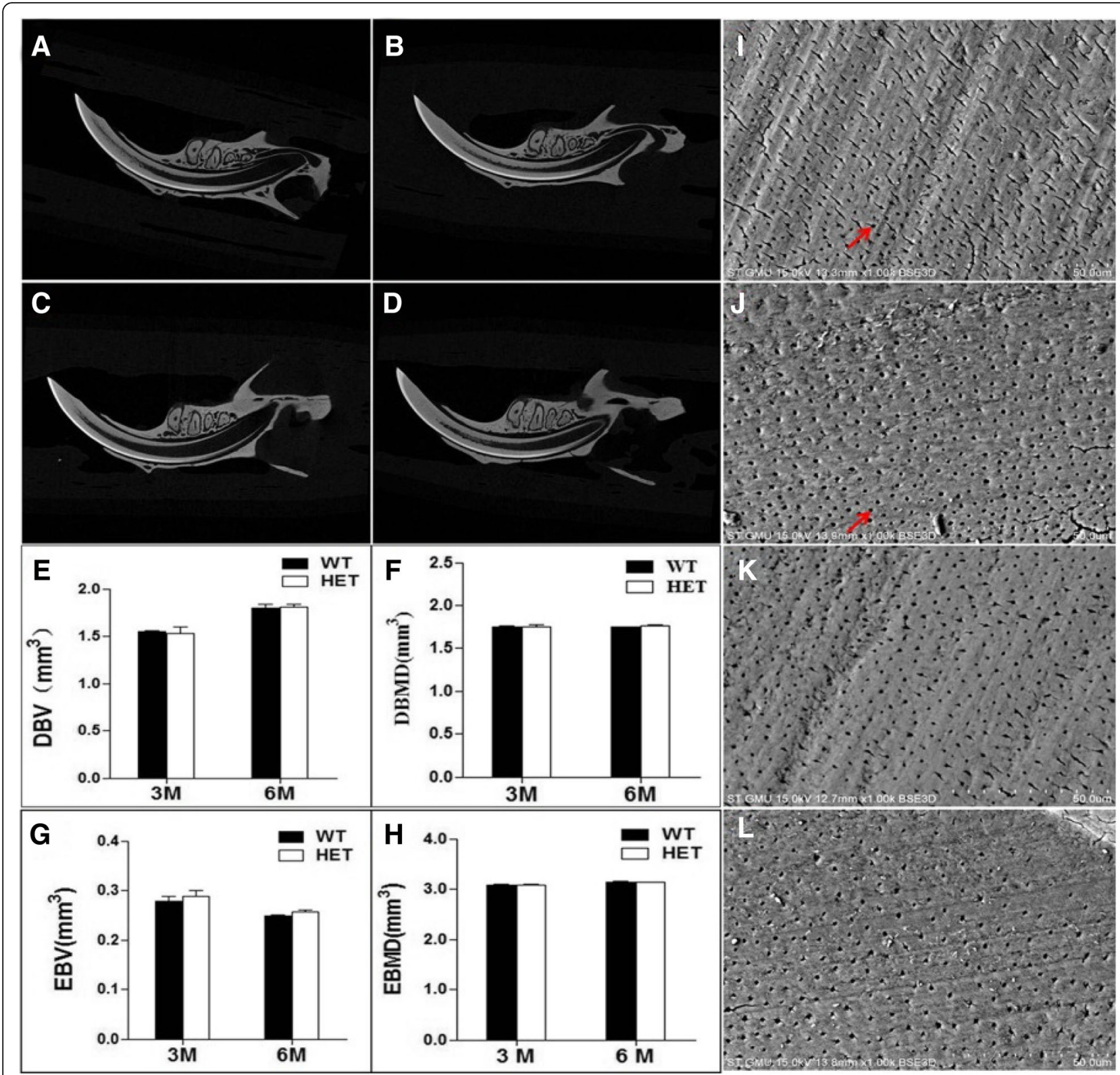

Fig. 4 Statistical results of microcomputed tomography of mouse teeth and dentinal tubular structures of molar dentin. $\mathbf{a}$, b Representative microcomputed tomography of a 3-month-old mouse tooth. $\mathbf{c}$, $\mathbf{d}$ Representative microcomputed tomography of a 6-month-old mouse tooth. $\mathbf{e}$, $\mathbf{f}, \mathbf{g}$, and $\mathbf{h}$ Statistical analysis of DBV, DBMD, EBV, and EBMD on microcomputed tomography of mouse teeth. There were no significant differences between WT mice and HET mice. $\mathbf{i}$, j Scanning electron microscopy of molar dentin in 3-month-old mice. $\mathbf{k}$, I Scanning electron microscopy of molar dentin in 6-month-old mice. The red arrows indicate the dentinal tubules. $\mathbf{a}, \mathbf{c}, \mathbf{i}$, and $\mathbf{k}$ are WT mice; $\mathbf{b}, \mathbf{d}$, $\mathbf{j}$, and I are HET mice. Abbreviations: DBV, dentin bone volume; DBMD, dentin bone mineral density; EBV, enamel bone volume; EBMD, enamel bone mineral density

We also examined the microscopic structure of teeth from 3- and 6-month-old mice by SEM, to determine the size and sparseness of dentin tubules in dentin cross sections. Both WT and HET mice had dentinal tubules that were normal and uniform in tubular structure (Fig. 4i-l).

We investigated the mineralization degree and morphological changes in the ribs, coccyx, and femurs of 3and 9-month-old mice (Fig. 5A). Micro-CT was also used to observe the ultrastructure of the femoral trabecular bones (Fig. 5B); no significant differences were found in any of the above features between WT and HET mice.

\section{Effects of the $V p s 4 B$ gene on skeletal structure}

$H \& E$ staining of mouse femurs was performed to observe abnormal changes in the trabecular bone (Fig. 6a, b) as 


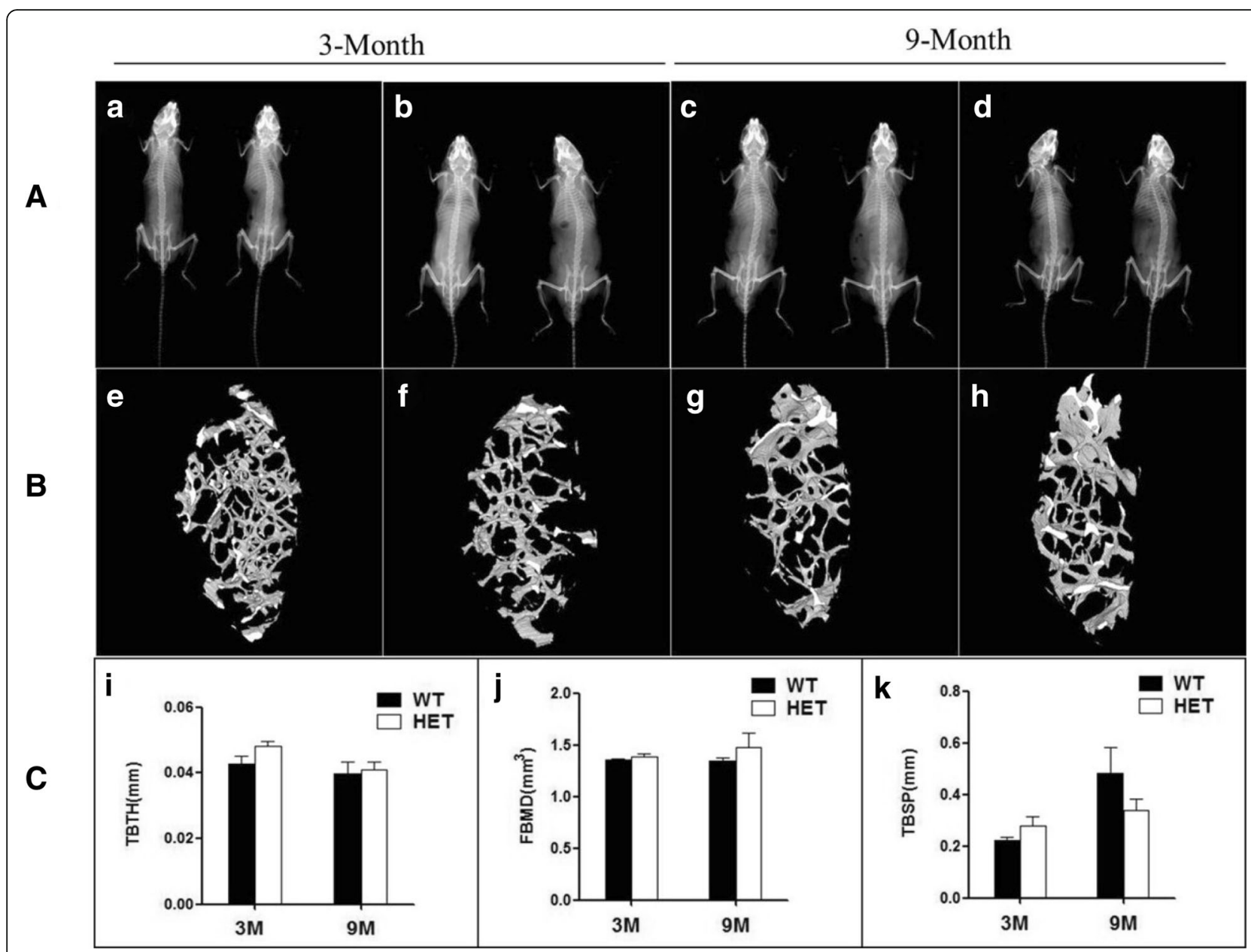

Fig. 5 Representative radiographs of mouse skeletal specimens and statistical analysis of trabecular bones analyzed by microcomputed tomography. A X-ray analysis of WT and HET mouse skeletal specimens. Two age groups (3- and 9-month-old mice) were analyzed for each genotype; WT mice are shown on the left side of each group; HET mice are shown on the right side. B Representative micro-CT 3-dimensional images of trabecular bones of WT mice (e, g) and HET mice $(f, h)$. C Statistical analysis of microcomputed tomography of mouse trabecular bones using TBTH, FBMD, and TBSP. Abbreviations: TBTH, trabecular thickness; FBMD, femoral bone mineral density; TBSP, trabecular separation

bone and dentin are similar in terms of composition and mineralization [15]. As the distance of the trabecular bone from the growth plate is directly related to its mineralization [16], the growth plate is taken as a reference point to observe the trabecular bone density.

We applied Alcian blue-Alizarin red staining of skeletal specimens to analyze the differences with respect to bones and cartilage between the different mice. No differences were found between the two genotypes (Fig. 6c).

\section{Discussion}

DD-I (OMIM: 125400) is a rare autosomal dominant dental dysplasia with a penetrance of less than $100 \%$ and an incidence of $1 / 10,000$ [17]. Clinical examination shows that the shape and color of teeth are normal, but dentin formation defects and medullary occlusion are often accompanied by a transmission shadow at the root apex in X-rays. Ballschmiede first described the disease in 1920, when he found that seven children from the same family had short, blunt tooth roots and premature tooth loss; a term he named conditional "non root teeth". Subsequently, mutations in the SMOC2 gene, SSHU2 gene and $V P S 4 B$ gene were found to be associated with DD-I $[13,18]$.

In this study, we compared HET mice to WT mice for differences in teeth and bone, as only HET mice with partial $V p s 4 b$ KO were obtained. Although the expression of VPS4B was reduced and the pre-dentin zone was increased in HET mice compared with WT mice, we did not find any differences in H\&E staining of bones, in microscopic results, or in X-ray results. We also used micro-CT to analyze changes in tooth mineralization and volume, as well as volume and density of trabecular bone, while SEM was used to analyze changes in dentinal tubules in the teeth of the two groups. However, no differences were found between HET and WT mice. 


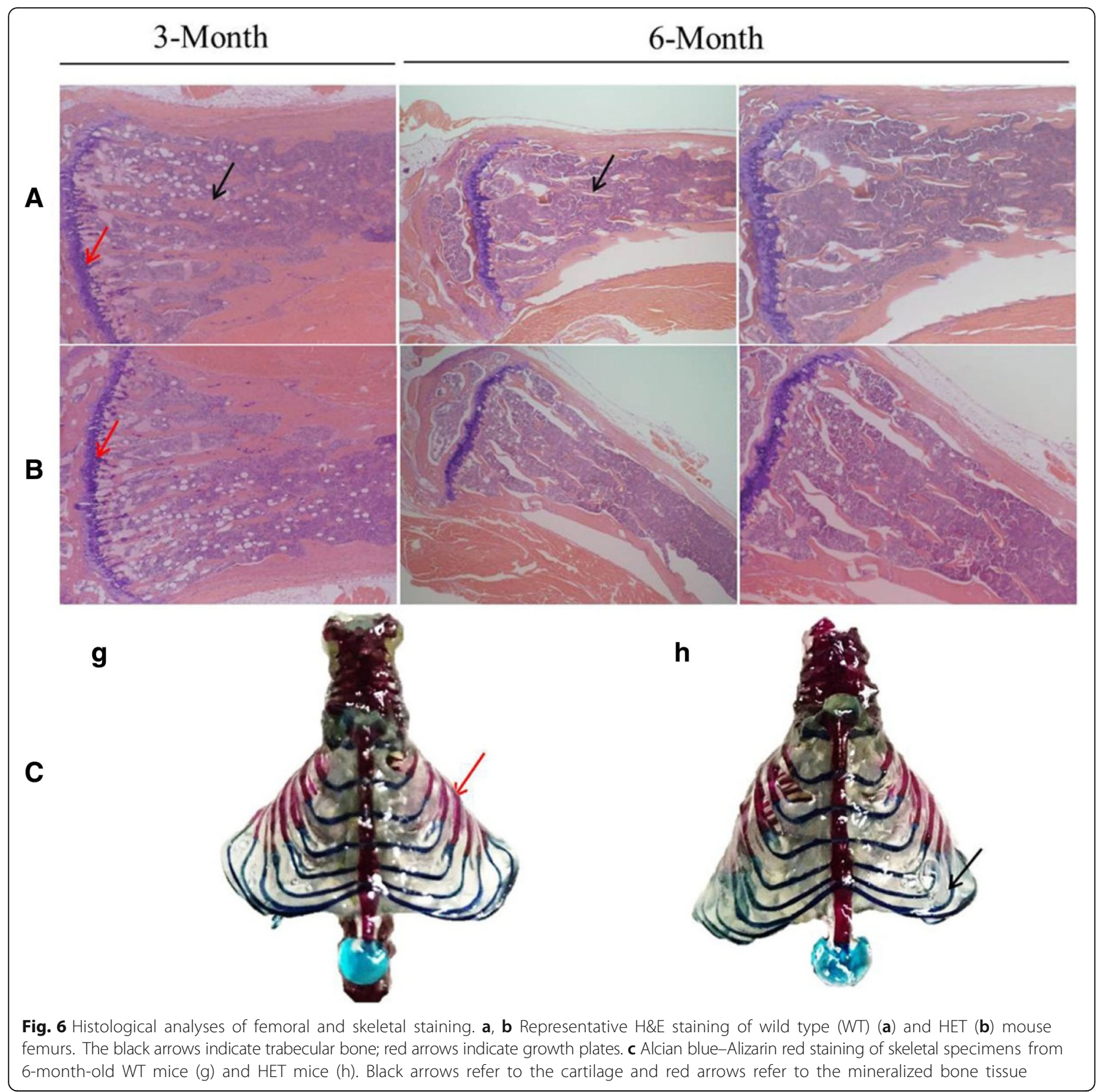

Differences in the phenotype caused by disruption of $V P S 4 B$ in human and mouse might be explained by several mechanisms: (1) The different tooth development patterns. It is already known that mouse teeth are constantly growing, a phenomenon which continues throughout life [5]; however, humans have two sets of teeth: deciduous teeth and permanent teeth. At the time of tooth emergence, the root is not fully formed, the medullary cavity is large, and the apical hole is flared open. The apical part is only completely formed at 2-3 years after tooth emergence. (2) The different molecular mechanisms regulating tooth development. Tooth development is a long and complex biological process and is closely related to the migration and directional differentiation of nerve cells [19-21]. There are four molecular signaling families which regulate tooth development, including: bone morphogenetic proteins (BMPs), fibroblast growth factors (FGFs), hedgehog protein family (Hhs) and Wnt signaling [2224]. Subtle differences in molecular regulation still exist between human and mouse tooth development. For example, FGF8, an important member of the FGF family, exists as four isoforms in the human body (FGF8a, FGF8b, FGF8e and FGF8f) [25]; however, there are eight isoforms in the mouse, named FGF8a-h [26]. Moreover, FGF8 is 
always expressed in the development of human teeth, while in mouse tooth development, it is initially expressed in the epithelium at the predetermined position before the development of teeth, until the early bud stage, after which it is no longer expressed [26]. In addition, $F R Z B$ is a key factor in the canonical Wnt signaling pathway for tooth development, which is expressed in the inner enamel epithelium in the human tooth germ family, while Frzb was not detected in the mouse tooth germ of El 15.5 [27]. (3) The differences in the genomes between human VPS4B and mouse Vps $4 b$. Of the $96 \%$ of mouse genome sequences studied, up to $99 \%$ can be found in humans. The mouse $V p s 4 b$ gene is known to contain six transcripts, among which only Vps4b-001 and Vps4b-002 transcripts encode translated proteins, and the amino acid sequences of $V p s 4 b-001$ and Vps4b-002 encoding regions are completely consistent, but only Vps4b-001 contains RefSeq sequences. By comparing the amino acid sequence of human $V P S 4 B$ protein and mouse $V p s 4 b-001$ protein, we found that the similarity between them was up to $95 \%$. Consequently we originally wanted to create a mouse that was consistent with the mutation (IVS7 $+46 \mathrm{C}>\mathrm{G}$ ) in the human VPS4B gene, but unfortunately, there was no such site in the mouse genome. Therefore we could not replicate the same mutation in the transgenic mouse. Instead, $\mathrm{KO}$ mice were constructed by knocking out $999 \mathrm{bp}$ of gDNA from the Vps4b gene. (4) The phenotypic changes in heterozygous mice might not be obvious. Because the homozygous allele was embryonic lethal, we were only able to generate Vps $4 b$ WT and heterozygous mice. Previous studies have reported that dentin matrix protein 1 (DMP1) and dentin sialophosphoprotein (DSPP) play crucial roles in dentin formation. Sreenath et al. deleted the entire DSPP coding region in embryonic stem cells and generated $\mathrm{Dspp}^{-1-}$ mice $[12,28]$. These null mice exhibited an enlarged pulp cavity, widened pre-dentin zone, decreased dentin width, and high incidence of pulp exposures, similar to type III dentinogenesis imperfecta (DGI-III). However, these differences were only found in homozygous mutants but not in heterozygous mutants. Similarly, it has been reported that similar defects were present in $D m p 1^{-1-}$ mice; however, there was no mention of the dental phenotype of heterozygous mice [29, 30]. We speculate the heterozygous mutations in dentin formationrelated genes are not sufficient to cause defects in the tooth phenotype in mice.

\section{Conclusion}

We speculate that this result is due to the fact that there are significant differences in tooth formation between mouse and human. In addition, it may be that phenotypic changes of the teeth of heterozygous mice are not obvious, and because we only obtained heterozygous mice, we were not able to see any significant differences in such phenotypic changes. Further investigation into the mechanisms of our experimental findings need to be carried out to determine whether mice are a suitable animal model to investigate human tooth diseases.

\section{Abbreviations \\ DD-I: Dentin dysplasia type I; DGI-III: Type III dentinogenesis imperfect; DMP1: Dentin matrix protein 1; DSPP: Dentin sialophosphoprotein; H\&E: Hematoxylin and eosin; HET: Heterozygous; IHC: Immunohistochemistry; KO: Knockout; Micro-CT: Microcomputed tomography; PCR: Polymerase chain reaction; SEM: Scanning electron microscopy; VPS4B: Vacuolar protein sorting- associated protein $4 \mathrm{~B}$; WT: Wild-type}

\section{Acknowledgements}

We gratefully acknowledge the contribution of participating individuals whose cooperation made this study possible.

\section{Funding}

This work was supported by grants from the National Natural Science Foundation of China (31371279) and Guangzhou Science and Technology Program key projects (201707010301). The funding body played no role in the design of the study and collection, analysis and interpretation of data, and in writing the manuscript.

Availability of data and materials

The datasets used and/or analyzed during the current study are available from the corresponding author on reasonable request.

\section{Authors' contributions}

$\mathrm{AQH}, \mathrm{DC2}, \mathrm{FX}$ : design; analysis and interpretation of data; drafting of the manuscript. $A Q H, T L, D C 1$ : implementation of experiments. JH, WWF, DG, YJL: drafting of the manuscript. $X M X, F X, A Q H$ : wrote the manuscript. $X M X, D C 2, F X$ : supervising the work. All authors have read and approved the manuscript.

\section{Ethics approval and consent to participate}

All procedures used in this study were approved by the Medical Ethics Committee of Nanfang Hospital, an affiliate of Southern Medical University, China

Consent for publication

Not applicable.

\section{Competing interests}

The authors declare that they have no competing interests.

\section{Publisher's Note}

Springer Nature remains neutral with regard to jurisdictional claims in published maps and institutional affiliations.

\section{Author details}

'Department of Medical Genetics, School of Basic Medical Sciences, Southern Medical University, No.1023, Shatai South Road, Guangzhou 510515, People's Republic of China. ${ }^{2}$ Department of Stomatology, Nanfang Hospital, Southern Medical University, Guangzhou 510515, China. ${ }^{3}$ Guangdong Provincial Key Laboratory of Single Cell Technology and Application, Guangdong 510515, China. ${ }^{4}$ Department of Stomatology, the First Affiliated Hospital of

Zhengzhou University, Zhengzhou 450052, China.

Received: 2 April 2018 Accepted: 22 November 2018

Published online: 11 January 2019

\section{References}

1. Cui G, Wang Y, Yu S, Yang L, Li B, Wang W, et al. The expression changes of vacuolar protein sorting 4 B (VPS4B) following middle cerebral artery occlusion (MCAO) in adult rats brain hippocampus. Cell Mol Neurobiol. 2014;34(1):83-94. 
2. Inoue M, Kamikubo H, Kataoka M, Kato R, Yoshimori T, Wakatsuki S, Kawasaki M. Nucleotide-dependent conformational changes and assembly of the AAA ATPase SKD1NPS4B. Traffic. 2008;9(12):2180-9.

3. Lin HH, Li X, Chen JL, Sun X, Cooper FN, Chen YR, et al. Identification of an AAA ATPase VPS4B-dependent pathway that modulates epidermal growth factor receptor abundance and signaling during hypoxia. Mol Cell Biol. 2012;32(6):1124-38.

4. Scheuring $S$, Röhricht RA, Schöning-Burkhardt B, Beyer A, Müller S, Abts HF, Köhrer K. Mammalian Cells Express Two VPS4 Proteins Both of Which are Involved in Intracellular Protein Trafficking. J Mol Biol. 2001; 312(3):469-80

5. $\mathrm{Li} \mathrm{CH}$, Li CZ. The role of hippo signaling in tooth development. J Formos Med Assoc. 2016;115(5):295-7.

6. Thesleff I, Vaahtokari A, Partanen AM. Regulation of organogenesis. Common molecular mechanisms regulating the development of teeth and other organs. Int J Dev Biol. 1995;39(1):35-50.

7. Beyer A, Scheuring S, Müller S, Mincheva A, Lichter P, Köhrer K. Comparative sequence and expression analyses of four mammalian VPS4 genes. Gene. 2003;305(1):47-59.

8. Stuchellbrereton MD, Skalicky JJ, Kieffer C, Karren MA, Ghaffarian S, Sundquist WI. ESCRT-III recognition by VPS4 ATPases. Nature. 2007; 449(7163):740-4.

9. Scott A, Chung HY, Gonciarz-Swiatek M, Hill GC, Whitby FG, Gaspar J, et al. Structural and mechanistic studies of VPS4 proteins. EMBO J. 2005; 24(20):3658-69.

10. Yang $Q$, Chen D, Xiong F, Chen D, Liu C, Liu Y, et al. A splicing mutation in VPS4B causes dentin dysplasia I. J Med Genet. 2016;53(9):624.

11. Xiong F, Ji Z, Liu Y, Zhang Y, Hu L, Yang Q, et al. Mutation in SSUH2 causes autosomal-dominant dentin dysplasia type I. Hum Mutat. 2017;38(1):95-104.

12. Gibson MP, Zhu Q, Wang S, Liu Q, Liu Y, Wang X, et al. The Rescue of Dentin Matrix Protein 1 (DMP1)-deficient tooth defects by the transgenic expression of dentin Sialophosphoprotein (DSPP) indicates that DSPP is a downstream effector molecule of DMP1 in Dentinogenesis. J Biol Chem. 2013;288(10):7204-14.

13. Choi SJ, Song IS, Feng JQ, Gao T, Haruyama N, Gautam P, Robey PG, Hart TC. Mutant DLX 3 disrupts odontoblast polarization and dentin formation. Dev Biol. 2010;344(2):682-92.

14. Li LL, Liu PH, Xie XH, Su M, Chao L, Li C, Qin CL. Loss of epithelial FAM20A in mice causes amelogenesis imperfecta, tooth eruption delay and gingival overgrowth. Int J Oral Sci. 2016;8(2):98-109.

15. Wang X, Wang J, Yuan B, Lu Y, Feng JQ, Qin C. Overexpression of Dmp1 fails to rescue the bone and dentin defects in Fam20C knockout mice. Connect Tissue Res. 2014;55(4):299-303.

16. Bo $Y$, Zhang $Z$, Jin $D$, Chen $C$, Jia $C$, Wen $L$, et al. mTORC1 regulates PTHrP to coordinate chondrocyte growth, proliferation and differentiation. Nat Commun. 2016;7:11151.

17. Barron MJ, Mcdonnell ST, Mackie I, Dixon MJ. Hereditary dentine disorders: dentinogenesis imperfecta and dentine dysplasia. Orphanet J Rare Dis. 2008;3(1):31.

18. Jaouad IC, Alloussi ME, Laarabi FZ, Bouhouche A, Ameziane R, Sefiani A. Inhabitual autosomal recessive form of dentin dysplasia type I in a large consanguineous Moroccan family. Eur J Med Genet. 2013;56(8):442-4.

19. Chai $Y$, Jiang $X$, Ito $Y$, Bringas $P$ Jr, Han J, Rowitch DH, Soriano $P, A P M M$, Sucov HM. Fate of the mammalian cranial neural crest during tooth and mandibular morphogenesis. Development. 2000;127(8):1671-9.

20. Dassule HR, Mcmahon AP. Analysis of epithelial-mesenchymal interactions in the initial morphogenesis of the mammalian tooth. Dev Biol. 1998; 202(2):215-27.

21. Thesleff I. Genetic basis of development of dental defects. Acta Odontol Scand. 2000;58(5):191-4.

22. Imai H, Osumiyamashita N, Ninomiya Y, Eto K. Contribution of earlyemigrating midbrain crest cells to the dental mesenchyme of mandibular molar teeth in rat embryos. Dev Biol. 1996;176(2):151-65.

23. Kontges $\mathrm{G}$, Lumsden $\mathrm{A}$. Rhombencephalic neural crest segmentation is preserved throughout craniofacial ontogeny. Development. 1996; 122(10):3229-42.

24. Zhang Y, Wang S, Song Y, Han J, Chai Y, Chen Y. Timing of odontogenic neural crest cell migration and tooth-forming capability in mice. Dev Dyn. 2003;226(4):713-8.

25. Gemel J, Gorry M, Ehrlich GD, Macarthur CA. Structure and sequence of human FGF8. Genomics. 1996;35(1):253-7.
26. Crossley PH, Martin GR. The mouse Fgf8 gene encodes a family of polypeptides and is expressed in regions that direct outgrowth and patterning in the developing embryo. Development. 1995;121(2):439-51.

27. Sarkar L, Sharpe P. Inhibition of Wnt signaling by exogenous Mfrzb1 protein affects molar tooth size. J Dent Res. 2000;79(4):920-5.

28. Sreenath T, Thyagarajan T, Hall B, Longenecker G, D'Souza R, Hong S, et al. Dentin sialophosphoprotein knockout mouse teeth display widened predentin zone and develop defective dentin mineralization similar to human dentinogenesis imperfecta type III. J Biol Chem. 2003;278(27): 24874-80.

29. Ye L, Macdougall M, Zhang S, Xie Y, Zhang J, Li Z, Lu Y, Mishina Y, Feng JQ. Deletion of dentin matrix protein-1 leads to a partial failure of maturation of predentin into dentin, hypomineralization, and expanded cavities of pulp and root canal during postnatal tooth development. J Biol Chem. 2004; 279(18):19141-8.

30. Sun Y, Lu Y, Chen L, Gao T, D'Souza R, Feng JQ, Qin C. DMP1 processing is essential to dentin and jaw formation. J Dent Res. 2011;90(5):619-24.

\section{Ready to submit your research? Choose BMC and benefit from:}

- fast, convenient online submission

- thorough peer review by experienced researchers in your field

- rapid publication on acceptance

- support for research data, including large and complex data types

- gold Open Access which fosters wider collaboration and increased citations

- maximum visibility for your research: over 100M website views per year

At BMC, research is always in progress.

Learn more biomedcentral.com/submissions 